\title{
General Practitioners' Propensity to Cooperate With Other Health Professionals in the Management of Patients With Multimorbidity and Polypharmacy: A Cross-sectional Study.
}

Helene Carrier ( $\boldsymbol{\sigma}$ hln.carrier@gmail.com )

Aix-Marseille Universite https://orcid.org/0000-0001-7421-9863

Anna Zaytseva

Aix-Marseille Universite

Aurélie Bocquier

Aix-Marseille Universite

Patrick Villani

Aix-Marseille Universite

Martin Fortin

Universite de Sherbrooke

Pierre Verger

Aix-Marseille Universite

Research article

Keywords: multimorbidity, polypharmacy, interprofessional relations, medication management, general practitioners, cross-sectional surveys

Posted Date: July 6th, 2020

DOI: https://doi.org/10.21203/rs.3.rs-33817/v1

License: (우 (1) This work is licensed under a Creative Commons Attribution 4.0 International License. Read Full License 


\section{Abstract}

Background. Cooperation between general practitioners (GPs) and other health professionals appears to help reduce the risk of adverse events linked to polypharmacy for patients with multimorbidity. We investigated the existence of different GP profiles according to their opinions and behaviors about such cooperation and studied the association between these profiles and the GPs' characteristics and deprescribing behaviors.

Methods. Between May and July 2016, we performed a cross-sectional survey in a panel of French GPsabout their management of patients with multimorbidity and polypharmacy, focusing specifically on their opinions of healthcare professionals' roles and interprofessional cooperation. We used an agglomerative hierarchical cluster analysis to identify GP profiles and then multivariable logistic regression models to study their associations with these doctors' characteristics and deprescribing behaviors.

Results. We identified four profiles of GPs according to their cooperation propensities: GPs from the "intensive" profile $(14 \%)$ were favorable to cooperating with various health professionals, including delegating some prescribing tasks to pharmacists; GPs from the "moderate" profile (47\%) had favorable opinions about health professionals' roles, except for this specific task delegation; GPs from the "selective" profile (27\%) tended to work only with physicians; GPs from the "low cooperation" profile (12\%) didn't appeared interested in cooperation. These profiles were associated with different professional characteristics.

Conclusions. Current health policies encourage interprofessional cooperation for the management of patients with multimorbidity. Our study provides information for understanding disparities among GPs regarding working with other professionals who deal with their patients and suggests possible ways to improve cooperation.

\section{Background}

Multimorbidity, defined as the coexistence of two or more diseases in the same individual [1], leads to polypharmacy, which is associated with several iatrogenic risks - including drug-drug interactions and adverse drug events - and premature mortality $[2,3]$. Multimorbidity also increases the use of primary and secondary healthcare services $[4,5]$, thus complicating the coordination of care by general practitioners (GPs) [6, 7]. The number of specialists involved in the management of patients with multimorbidity and their prescriptions also increases the risk of adverse drug events [3]. GPs must regularly review the prescriptions of patients with multimorbidity and polypharmacy and may need to deprescribe medications with an unfavorable risk-benefit balance. Interprofessional management of polypharmacy involving case managers, nurse practitioners, or pharmacists, can decrease potentially inappropriate prescriptions [8], especially when it involves prescription review by pharmacists $[9,10]$. Effective cooperation between GPs and other health professionals may also improve these patients' functional status, professionals' adherence to recommended practices, and the quality of GPs' practices (e.g., monitoring of patients with diabetes, or benzodiazepine prescriptions following guidelines) [11].

Accordingly, health policies in several countries encourage interprofessional cooperation and multiprofessional practices (e.g., multidisciplinary or multiprofessional group practices and healthcare networks) [12-14]. Several qualitative studies have addressed these professionals' experiences and perceptions of such cooperation $[7,15$, 16]. But little is known about how and the extent to which GPs cooperate with other healthcare professionals 
(medical specialists and non-physician professionals as pharmacists, nurses, physical therapists etc) and in managing patients with multimorbidity and polypharmacy, and whether their propensity to cooperate may influence their own practices.

This study's objectives included the: 1) identification of different profiles of GPs, according to their opinions and attitudes towards cooperation with other healthcare professionals when managing this patient population; 2) study of the personal and professional characteristics of GPs associated with these profiles; and 3) the assessment of whether such profiles are associated with a propensity for deprescribing.

\section{Methods}

\section{Design and population}

We conducted a cross-sectional survey about the management of patients with multimorbidity and polypharmacy, nested in a panel of GPs in private practice in France. The panel design has been described in previous publications $[17,18]$. In brief, we randomly selected GPs from the exhaustive French database of health professionals (Répertoire Partagé des Professionnels de Santé) between December 2013 and March 2014. The sampling was stratified for age, sex, annual number of consultations and house calls, and medical density of each GP's municipality of practice. We excluded GPs with fewer than 5 patient visits weekly, those planning to retire within 6 months, and those practicing exclusively alternative medicine (e.g., acupuncture or homeopathy). At inclusion, participants answered a short questionnaire about their professional characteristics. The subsequent interview later included questions about their practice organization: solo practice (GP practicing alone in a single office), group practice (several physicians practicing together), and multiprofessional practice (GPs working with several health professionals including nurses, physical therapists, psychologists, etc).

\section{Data collection procedure and questionnaire}

Professional interviewers used a computer-assisted telephone interview system to collect data between May and July 2016 with a standardized questionnaire. It was developed with a multidisciplinary group of experts, based on a literature review and the results of two qualitative focus groups, one of four and the other of five GPs. We pilot-tested the questionnaire among $50 \mathrm{GPs}$ to clarify and validate the questions.

We defined multimorbidity as the presence of multiple chronic diseases in a single person. The questionnaire addressed GPs' opinions about their role and that of medical specialists (e.g. cardiologists, endocrinologists etc.) in the management of prescriptions in patients with multimorbidity and their opinions about their cooperation with pharmacists regarding polypharmacy (4-point Likert scale from strongly disagree to strongly agree, see Additional File). We asked GPs about the frequency of contacts with specialists or pharmacists for medication management (4-point Likert-like scale: never, sometimes, often, and very often), and the usefulness of other non-physician health professionals' participation in the management of these patients (Yes/No). We also asked GPs about their propensity to initiate the deprescription of medications they consider inappropriate (4-point Likert-like scale: never, sometimes, often, and very often). A "don't know" answer was also proposed for each question.

\section{Statistical analysis}


Data were weighted to match the national GP population according to the stratification variables. For objective 1, multiple correspondence analysis (MCA) was used as a pre-processing step for further cluster analysis: this allows to reduce the dimensionality of the data and to transform categorical variables into continuous ones (factor coordinates). Then results we conducted an agglomerative hierarchical cluster analysis (AHCA) to identify cooperation clusters (profiles) of GPs, according to their opinions and behaviors regarding cooperation with other health professionals (Additional file contains the items included in the analysis). We used the minimum inertia lost to identify the optimal number of clusters; this corresponds to a minimal within-cluster variance (individuals with maximum similarity in each cluster) and a maximal inter-cluster variance. Some items used for MCA and AHCA analyses had categories accounting for less than 10\% of the answers. These categories were then regrouped with the closest category (e.g., often/very often). The "don't know" answers were excluded from the analyses.

For objective 2, we used the cooperation clusters as dependent variables and conducted multinomial logistic regressions to study their associations with GPs' personal and professional characteristics (age, sex, practice organization and participation in a continuing medical education (CME) course). Logistic regressions were adjusted for workload, medical density and reported proportion of patients with multimorbidity on GP's list.

Finally, for objective 3, we studied whether the cooperation clusters (the variable of interest) were associated with GPs' propensity to deprescribe medications they considered inappropriate (dependent variable). We used a multivariable logistic regression model, adjusted for GPs' stratification variables (age, sex, workload, and the medical density in their practice area).

All analyses were based on two-sided $P$ values, with statistical significance defined by $P \leq .05$; they were conducted with SAS 9.4 statistical software (SAS Institute, Cary, NC).

\section{Results}

Of the 3724 eligible GPs, 1712 (46.0\%) agreed to join the panel in 2014, of which 1266 (73.9\%) were still participating at the time of this survey in 2016 . Among them, 1183 (93.4\%) completed the multimorbidity/polypharmacy questionnaire. Table 1 describes the participants' characteristics. 
Table 1

Characteristics of the sample from the national panel of GPs, France, May-September 2016 (descriptive analyses of weighted data)

\section{$n(N=1183) \quad$ Frequency, $\%$}

\section{Stratification variables}

Age at inclusion in years (tertiles)

$<50$

362

30.6

$50-58$

386

32.6

$>58$

435

36.8

Sex

Women

363

30.7

Workload (number of consultations/visits from December 2011 to November 2012)

$<3067$

294

24.8

$3067-6028$

592

50.1

$>6028$

297

25.1

GP density of the municipality of practice in 2012

$<-19.3 \%$ of the national average

296

25.0

$-19.3 \%$ to $+17.7 \%$ of the national average

591

50.0

$>+17.7 \%$ of the national average

296

25.0

\section{Professional characteristics}

Practice organization in 2016*

Solo practice

537

49.4

Group practice $^{a}$

482

44.3

Multiprofessional practice ${ }^{b}$

69

Participated in a continuing medical education (CME) course in 2012†

No

133

Yes

996

84.2

Self-reported proportion of patients with multimorbidity on GP’s listł

$\begin{array}{lrr}<25 \% & 501 & 42.9 \\ 25 \%-50 \% & 497 & 42.5 \\ >50 \% & 170 & 14.6\end{array}$


$\mathrm{GP}=$ general practitioner

* Data from the third survey of the national panel, 95 missing data

a Practice organization where many physicians work together

b Practice organization where GPs work with several health professionals (nurses, physical therapists, psychologists, specialists, etc)

† 54 missing data

$\ddagger 15$ "no answer"

\section{GPs' profiles regarding interprofessional cooperation}

The cluster analysis identified four profiles of GPs, based on their opinions about different professionals' roles regarding the management of patients with multimorbidity and polypharmacy and their behaviors and opinions about cooperation with these professionals (Table 2). GPs from the first profile ( $14 \%$ of the sample, intensive cooperation profile) had favorable opinions about the roles of both specialists and other healthcare professionals in the management of this patient population and about their cooperation with them. Only this group had a majority $(71 \%)$ agreeing with the delegation to pharmacists of medication management (prescription review and modification). GPs from the second profile (47\%, moderate cooperation) had more positive opinions than average about pharmacists' knowledge and role in managing polypharmacy, but they were nonetheless mainly opposed to letting pharmacists modify patients' prescriptions. They were more favorable than average to cooperation with various health professionals for the management of these patients, including delegation of consultations to nurses, but had more negative opinions than average about specialists' role in this management. GPs from the third profile ( $27 \%$, selective cooperation profile) were likely to cooperate with other physicians and had more positive views than average about specialists' roles in medication management. They tended to oppose the delegation of prescriptions to nurses or pharmacists and had unfavorable opinions about the role and cooperation of pharmacists. GPs from the last profile $(12 \%$, low cooperation profile) expressed the most frequent negative opinions of cooperation, task delegation, and other professionals' roles in the management of polypharmacy. 
Table 2

Profiles of GPs according to their opinions and behaviors about collaboration with health professionals for management of patients with multimorbidity and polypharmacy.

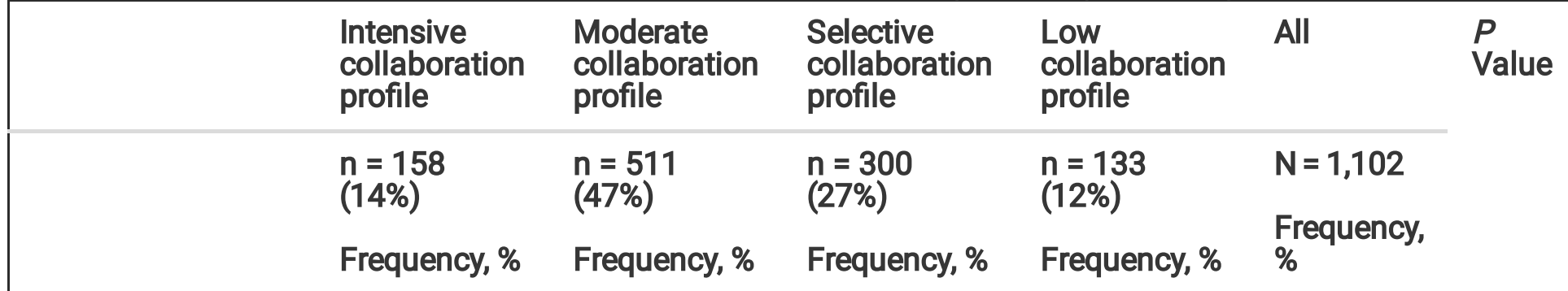

GP's opinion about their role and that of specialists in the management of prescriptions

You are the one who decides the prescriptions, even for medications initially prescribed by another physician

$\begin{array}{lllllll}\text { Agree/Strongly } & 84.2 & 75.3 & 80.9 & 76.4 & 78.3 & .09\end{array}$

agree

You feel you are well informed about all medications taken by your patients with multimorbidity
Agree/Strongly
83.1
76.1
93.5
86.9
83.3
$<.001$
agree

Specialists are well informed about all medications taken by their patients
Agree/Strongly
58.0
40.9
67.6
37.8
50.3
$<.001$
agree

Management of patients with multimorbidity by different specialists increases the risk of drug interactions

$\begin{array}{lllllll}\begin{array}{l}\text { Strongly } \\ \text { disagree/Disagree }\end{array} & 12.9 & 4.5 & 38.2 & 8.2 & 15.3<.001\end{array}$

\section{GPs' opinions about pharmacists' role and collaboration with them}

The pharmacist is the professional who knows all patients' medications best
Agree/Strongly
91.7
73.5
56.1
70.8
71.2
$<.001$
agree

GPs and pharmacists don't collaborate enough on patients' polypharmacy
Agree/Strongly
54.3
75.3
38.7
69.2
61.4
$<.001$
agree

You expect the pharmacist to warn you of drug-interaction risks among a patient's prescriptions

$\begin{array}{lllllll}\begin{array}{l}\text { Agree/Strongly } \\ \text { agree }\end{array} & 95.2 & 93.5 & 87.2 & 90.7 & 91.7 & <.001\end{array}$

GPs' behaviors about the collaboration with various health professionals

Usefulness of meeting with patients' other health professionals

$\begin{array}{lllllll}\text { Yes } & 70.7 & 80.9 & 42.2 & 46.5 & 64.4 & <.001\end{array}$

To learn what medications have been prescribed to a patient, you call the pharmacist

$\begin{array}{lllllll}\text { Often/very often } & 61.4 & 60.1 & 46.0 & 25.8 & 52.1 & <.001\end{array}$




\begin{tabular}{|c|c|c|c|c|c|c|}
\hline & $\begin{array}{l}\text { Intensive } \\
\text { collaboration } \\
\text { profile }\end{array}$ & $\begin{array}{l}\text { Moderate } \\
\text { collaboration } \\
\text { profile }\end{array}$ & $\begin{array}{l}\text { Selective } \\
\text { collaboration } \\
\text { profile }\end{array}$ & $\begin{array}{l}\text { Low } \\
\text { collaboration } \\
\text { profile }\end{array}$ & All & \multirow[t]{3}{*}{$\stackrel{P}{\text { Value }}$} \\
\hline & $\begin{array}{l}n=158 \\
(14 \%)\end{array}$ & $\begin{array}{l}n=511 \\
(47 \%)\end{array}$ & $\begin{array}{l}n=300 \\
(27 \%)\end{array}$ & $\begin{array}{l}n=133 \\
(12 \%)\end{array}$ & \multirow{2}{*}{$\begin{array}{l}\mathrm{N}=1,102 \\
\text { Frequency, } \\
\%\end{array}$} & \\
\hline & Frequency, \% & Frequency, \% & Frequency, \% & Frequency, \% & & \\
\hline \multicolumn{7}{|c|}{ To learn what medications have been prescribed to a patient, you call the physician who prescribed them } \\
\hline Often/very often & 48.5 & 48.2 & 50.4 & 26.9 & 46.1 & $<.001$ \\
\hline \multicolumn{7}{|c|}{ GPs' opinions about professional delegation } \\
\hline \multicolumn{7}{|c|}{ The pharmacist has enough information to modify patient's medications } \\
\hline $\begin{array}{l}\text { Agree/Strongly } \\
\text { agree }\end{array}$ & 71.2 & 2.7 & 0.5 & 5.8 & 12.9 & $<.001$ \\
\hline \multicolumn{7}{|c|}{ Usefulness of consultations by nurses for patients with chronic diseases } \\
\hline Yes & 72.3 & 69.8 & 43.9 & 42.4 & 59.6 & $<.001$ \\
\hline
\end{tabular}

\section{Associations between GPs' profiles, their characteristics, and deprescribing propensity}

Multinomial logistic regression (Table 3) with the low cooperation profile as the reference, showed that GPs with a moderate cooperation profile were the youngest. The latter, together with those with an intensive cooperation profile, were also more likely to have participated in CME course. GPs' profiles were not associated with their workload, their medical density, or the self-reported proportions of patients with multimorbidity on their lists. They were not associated with practicing in multiprofessional groups, but those with an intensive cooperation profile worked less frequently in group practices. Finally, GPs' propensity to deprescribe inappropriate medications was lower in the moderate and selective cooperation profiles than in the low cooperation profile, but the association was not strong (Table 4). 
Table 3

Association between GPs' profiles according to their opinions and behaviors about collaboration and their personal and professional characteristics.

\begin{tabular}{|c|c|c|c|c|c|c|}
\hline \multirow[b]{3}{*}{ Characteristics } & \multicolumn{6}{|c|}{ GPs' profiles (ref. Low collaboration profile) } \\
\hline & \multicolumn{2}{|c|}{$\begin{array}{l}\text { Intensive collaboration } \\
\text { profile }\end{array}$} & \multicolumn{2}{|c|}{$\begin{array}{l}\text { Moderate collaboration } \\
\text { profile }\end{array}$} & \multicolumn{2}{|c|}{$\begin{array}{l}\text { Selective collaboration } \\
\text { profile }\end{array}$} \\
\hline & $\mathrm{aOR} *(95 \% \mathrm{Cl})$ & Palue & $\mathrm{aOR} *(95 \% \mathrm{Cl})$ & $\begin{array}{l}P \\
\text { Value }\end{array}$ & $\mathrm{aOR}^{*}(95 \% \mathrm{Cl})$ & $\begin{array}{l}\mathrm{P} \\
\text { Value }\end{array}$ \\
\hline \multicolumn{7}{|c|}{ Age at inclusion in years (ref. <50) } \\
\hline $50-58$ & $\begin{array}{l}0.79(0.42- \\
1.48)\end{array}$ & 0.46 & $\begin{array}{l}0.63(0.38- \\
1.04)\end{array}$ & 0.07 & $\begin{array}{l}0.74(0.43- \\
1.28)\end{array}$ & 0.28 \\
\hline$>58$ & $\begin{array}{l}0.78(0.39- \\
1.56)\end{array}$ & 0.48 & $\begin{array}{l}0.45(0.25- \\
0.80)\end{array}$ & 0.007 & $\begin{array}{l}0.75(0.40- \\
1.37)\end{array}$ & 0.35 \\
\hline \multicolumn{7}{|l|}{ Sex (ref. Men) } \\
\hline Women & $\begin{array}{l}1.14(0.63- \\
2.06)\end{array}$ & 0.67 & $\begin{array}{l}1.56(0.96- \\
2.53)^{(}\end{array}$ & 0.07 & $\begin{array}{l}1.44(0.85- \\
2.42)\end{array}$ & 0.17 \\
\hline \multicolumn{7}{|c|}{ Practice organization in $2016+$ (ref. Solo practice) } \\
\hline Group practice ${ }^{a}$ & $\begin{array}{l}0.52(0.30- \\
0.90)\end{array}$ & 0.02 & $\begin{array}{l}0.77(0.49- \\
1.20)\end{array}$ & 0.24 & $\begin{array}{l}0.72(0.45- \\
1.16)\end{array}$ & 0.18 \\
\hline $\begin{array}{l}\text { Multiprofessional } \\
\text { practice }^{\mathrm{b}}\end{array}$ & $\begin{array}{l}2.09(0.54- \\
8.14)\end{array}$ & 0.29 & $\begin{array}{l}2.98(0.87- \\
10.25)\end{array}$ & 0.08 & $\begin{array}{l}1.78(0.48- \\
6.58)\end{array}$ & 0.38 \\
\hline \multicolumn{7}{|c|}{ Participated in a continuing medical education course in 2012 (ref. No) } \\
\hline Yes & $2.09(1.00-4.37)$ & 0.05 & $\begin{array}{l}2.77(1.52- \\
5.03)^{(1)}\end{array}$ & $<.001$ & $\begin{array}{l}1.32(0.73- \\
2.39)\end{array}$ & 0.36 \\
\hline \multicolumn{7}{|c|}{$\mathrm{GP}=$ general practitioner, $\mathrm{aOR}=$ adjusted odds ratio, $\mathrm{Cl}=$ confidence interval } \\
\hline \multicolumn{7}{|c|}{$\begin{array}{l}\text { * Multinomial logistic regressions ( } N=953 \text {, non-weighted data) adjusted for workload, medical density, } \\
\text { reported proportion of patients with multimorbidity on GP's list }\end{array}$} \\
\hline \multicolumn{7}{|c|}{ † Data from the third survey of the national panel } \\
\hline \multicolumn{7}{|c|}{ a Practice organization where many physicians work together } \\
\hline $\begin{array}{l}\text { b Practice organiza } \\
\text { psychologists, spe }\end{array}$ & $\begin{array}{l}\text { n where GPs wor } \\
\text { lists, etc) }\end{array}$ & ith s & health prof & & Dhysical the & \\
\hline
\end{tabular}


Table 4

Association between GPs' deprescribing behavior and their profile according to their opinions and behaviors about collaboration.

\begin{tabular}{|c|c|c|}
\hline & \multicolumn{2}{|c|}{$\begin{array}{l}\text { Initiation of deprescription of medications considered potentially } \\
\text { inappropriate }\end{array}$} \\
\hline & \multicolumn{2}{|c|}{ (ref. Never/sometimes) } \\
\hline & \multicolumn{2}{|l|}{$N=1091$} \\
\hline & $\mathrm{aOR}^{*}(95 \% \mathrm{Cl})$ & $P$ Value \\
\hline \multicolumn{3}{|c|}{ GPs' collaboration profile (ref. Low collaboration profile) } \\
\hline $\begin{array}{l}\text { Intensive collaboration } \\
\text { profile }\end{array}$ & $0.86(0.54-1.39)$ & 0.57 \\
\hline $\begin{array}{l}\text { Moderate collaboration } \\
\text { profile }\end{array}$ & $0.64(0.43-0.96)$ & 0.03 \\
\hline $\begin{array}{l}\text { Selective collaboration } \\
\text { profile }\end{array}$ & $0.65(0.42-0.99)$ & 0.05 \\
\hline \multicolumn{3}{|c|}{$\mathrm{GP}=$ general practitioner, $\mathrm{aOR}=$ adjusted odds ratio, $\mathrm{Cl}=$ confidence interval } \\
\hline \multicolumn{3}{|c|}{$\begin{array}{l}\text { * Multivariable logistic regressions, adjusted for GPs' age, sex, workload, and medical density (non-weighted } \\
\text { data) }\end{array}$} \\
\hline
\end{tabular}

\section{Discussion}

We found various profiles of GPs' propensity to cooperate and share the management of prescriptions for patients with multimorbidity and polypharmacy with specialists and other health professionals. While most GPs recognized pharmacists' knowledge about medications and their adverse reactions, only a minority would agree to share prescription management with them.

GPs belonging to cooperative profiles (moderate and intensive) profiles had taken more CME courses than those in the low cooperation profile. GPs' propensity to initiate the deprescription of inappropriate medications was weakly correlated with their propensity to cooperate.

\section{Comparison with literature}

Qualitative studies have shown that some GPs feel that the involvement of many specialists in the management of these complicated patients results in the fragmentation of care. Combined with a lack of communication between physicians, this may lead to increase harm from polypharmacy $[7,15]$. In these qualitative studies, many GPs call for better interprofessional communication and a fair balance between them and specialists when sharing prescribing activity $[15,16]$. Our quantitative study confirmed that cooperation and confidence between physicians is not obvious for a majority of GPs (moderate and low cooperation profiles).

General practitioners would preferentially transfer to nurses, and sometimes pharmacists, advice to patients (lifestyle habits, monitoring of illnesses) and therapeutic education [19, 20]. 
Our results highlight the diversity of GPs' opinions about the role of pharmacists in the management of polypharmacy. Previous studies have demonstrated that pharmacists' involvement in medication management may result in better clinical outcomes and improvement of prescribing patterns, especially for patients with polypharmacy [21-23]. Their involvement in patient counselling, therapeutic education or the training of other health professionals would have a positive impact on the patients follow-up, their treatment adherence and their quality of life [22]. In the same time, the frequent limitation of cooperation between GPs and pharmacists to clarification of prescriptions, drug-related information, or information about patient history reduces its potential benefits [24-26]. Moreover, contacts are occasional and mostly at the pharmacists' initiative. Nevertheless, pharmacists and GPs share the opinion that cooperation is easier when they have a local, long-lasting working relationship $[25,27]$.

Our finding that a majority of GPs were favorable to practice nurses ensuring consultations for patients with chronic diseases is encouraging. A recent Cochrane review showed that nurse practitioners achieved equal or better outcomes for chronic patients than primary care doctors, in terms of quality of care, patient health status, and patient satisfaction [28].

The younger age of GPs with a moderate cooperation profile, compared with the others, probably reflects the shaping of attitudes and behaviors regarding interprofessional cooperation by years of experience and professional environment: more experienced GPs may have adjusted their role, given what they have learned to expect from other health professionals in their environment.

The absence of association between GPs' profiles and multiprofessional practice organization is surprising. But our study focused especially on the roles of specialists and pharmacists, who are rarely integrated in such organizations in France. Moreover, multiprofessional and group practices themselves have various profiles of organization and interprofessional collaboration [29, 30].

We found that GPs with profiles of moderate or selective cooperation had lesser deprescription propensities. At the same time, GPs with low and intensive cooperation profiles had similar behaviors towards deprescription. Qualitative studies have indicated that some GPs fear conflicts with other physicians or pharmacists when they initiate deprescription $[15,31]$. One hypothesis is that GPs who cooperate intensively discuss and share the responsibility for the prescription management with other professionals and might thus feel themselves supported and confident when deprescribing. Inversely, GPs with a low cooperation profile may prefer to take on the responsibility for prescriptions management including when deprescribing. This may be problematic especially when they face therapeutic dilemmas, in which they could benefit from the advice and insight of colleagues and other professionals.

\section{Strengths And Limitations}

The size of our sample was substantial. Moreover, we weighted the data according to some GP characteristics to minimize any selection bias. The method we used, AHCA, enabled us to study the statistical proximity of individuals on the basis of the factors under study, without any preconceptions about any relations among these factors. This analysis allows the identification of clusters of GPs assessed for several factors. 
Among the limitations, GPs' opinions and behaviors related to interprofessional cooperation with and the roles of other healthcare professionals were self-reported. We could not measure real collaboration practices, which would have required a more complex design. Thus, social desirability or conformity biases cannot be ruled out.

\section{Practice and policy implications}

Health policies in various countries are promoting interprofessional cooperation $[11,13,14]$ to improve the quality of primary care and patient health, especially for the patient population considered here [32]. Our study highlighted the diversity of GPs' points of view about cooperation with other healthcare professionals and about sharing prescription management for these. Although most GPs were favorable to interprofessional cooperation, they were also largely reluctant to delegate prescription tasks. This reflects both their strong attachment to the symbolic act of prescription and their defensiveness about other professionals in relation to fields of competence and responsibilities $[15,24]$. Policy makers must be aware of these disparities and difficulties.

Better cooperation requires better communication and better understanding of each other's' roles, knowledge, and responsibilities $[15,24,27]$. Our results indicate that most cooperative GPs have an interest in continuing training. The inclusion of multiprofessional courses in training programs for health students in medicine, pharmacy, nursing, and other disciplines, may lead to a better comprehension of the roles and skills of each profession and of the potential synergies to be gained in interprofessional cooperations $[8,33]$. The rapid development of multiprofessional medical centers in France and elsewhere is an opportunity to stimulate and facilitate such collaborations.

\section{Conclusion}

Disparities exist among GPs regarding the interprofessional cooperation in the management of patients with multimorbidity and polypharmacy. The majority of GPs are inclined to cooperate with other health professionals, but not in the same way, not with the same professionals, and very few go so far as to share prescription management with non-physician professionals. Interprofessional education, whether initial or continuing, may be one way to improve knowledge and understanding of each professional's roles and skills in the management of complex patients.

\section{Abbreviations}

AHCA

agglomerative hierarchical cluster analysis

CME

continuing medical education

GP

general practitioner

MCA

multiple correspondence analysis

\section{Declarations}


Ethics approval and consent to participate:A consent to participate was obtained from each general practitioner at the time of the inclusion in the panel. The National Authority for Statistical Information (Commission Nationale de l'InformationStatistique) approved the panel and its surveys (Paris, June the 3rd 2013, $n^{\circ} 82$ /H030). This national institution evaluated that the study was in accordance with the rules and regulations regarding the protection of personal data.

Consent for publication:Not applicable.

Availability of data and materials: The datasetsused and analysedduring the currentstudy are availablefrom the correspondingauthor on reasonablerequest. Descriptive analysis of data used in the currentstudy are in an additional file.

Competing interests:The authors declare that they have no competing interests.

Funding: The National Panel of GPs and its surveys were funded by: DREES (Direction for Research, Studies, Evaluation and Statistics); Ministère des affaires sociales et de la santé (Ministry of Health and Social Services); INPES (National Institute of Prevention and Education for Health); INSERM (National Institute of Health and Medical Research); ANSM (National Agency for Drug's and Health Produces' Safety).

The office of health professionals from the DREES contributed to the data weighting. The other funders were not included in the study design or analysis.

Authors' contributions: $\mathrm{HC}, \mathrm{AB}$ and P.Vergerdesigned and conceptualized the study and the analysis, they developed the questionnaire, theycoordinated and supervised the data collection, they interpreted the data analysis. AZ conceptualized and made the data analysis and revised the manuscript. HC wrote the manuscript. $A B$ critically reviewed and revised the manuscript. P.Verger designed the national panel, he critically reviewed and revised the manuscript. P. Villani revised the manuscript. MF contributed to the construction of the questionnaire and revised the manuscript.

All authors read and approved the final manuscript.

Acknowledgments: We thank GwenaëlleMaradan and her survey team from ObservatoireRégional de la Santé, Jo Ann Cahn for revising our manuscript for English language, and all GPs on the panel.

\section{References}

1. Valderas JM, Starfield B, Sibbald B, Salisbury C, Roland M. Defining Comorbidity: Implications for Understanding Health and Health Services. Ann Fam Med. 2009;7:357-63.

2. Fried TR, O'Leary J, Towle V, Goldstein MK, Trentalange M, Martin DK. Health Outcomes Associated with Polypharmacy in Community-Dwelling Older Adults: A Systematic Review. J Am Geriatr Soc. 2014;62:2261-72.

3. Calderón-Larrañaga A, Poblador-Plou B, González-Rubio F, Gimeno-Feliu LA, Abad-Díez JM, Prados-Torres A. Multimorbidity, polypharmacy, referrals, and adverse drug events: are we doing things well? Br J Gen Pract. 2012;62:821-6. 
4. Cassell A, Edwards D, Harshfield A, Rhodes K, Brimicombe J, Payne R, et al. The epidemiology of multimorbidity in primary care: a retrospective cohort study. Br J Gen Pract. 2018;68:e245-51.

5. Salisbury C, Johnson L, Purdy S, Valderas JM, Montgomery AA. Epidemiology and impact of multimorbidity in primary care: a retrospective cohort study. Br J Gen Pract. 2011;61:12-21.

6. Vogeli C, Shields AE, Lee TA, Gibson TB, Marder WD, Weiss KB, et al. Multiple Chronic Conditions: Prevalence, Health Consequences, and Implications for Quality, Care Management, and Costs. J Gen Intern Med. 2007;22:391-5.

7. Sinnott C, Mc Hugh S, Browne J, Bradley C. GPs' perspectives on the management of patients with multimorbidity: systematic review and synthesis of qualitative research. BMJ open. 2013;3:e003610.

8. Mecca MC, Thomas JM, Niehoff KM, Hyson A, Jeffery SM, Sellinger J, et al. Assessing an Interprofessional Polypharmacy and Deprescribing Educational Intervention for Primary Care Post-graduate Trainees: a Quantitative and Qualitative Evaluation. J Gen Intern Med. 2019;34:1220-7.

9. Campins L, Serra-Prat M, Gózalo I, López D, Palomera E, Agustí C, et al. Randomized controlled trial of an intervention to improve drug appropriateness in community-dwelling polymedicated elderly people. Fam Pract. 2017;34:36-42.

10. Köberlein-Neu J, Mennemann H, Hamacher S, Waltering I, Jaehde U, Schaffert C, et al. Interprofessional Medication Management in Patients With Multiple Morbidities. Dtsch Arztebl Int. 2016;113:741-8.

11. Reeves S, Pelone F, Harrison R, Goldman J, Zwarenstein M. Interprofessional collaboration to improve professional practice and healthcare outcomes. Cochrane Database Syst Rev. 2017;6:CD000072.

12. Mousquès J, Daniel F. The Impact of Multiprofessional Group Practices on the Quality of General Practice. Results of the Evaluation of Multidisciplinary Group Practices (MGP), Health Care Networks (HCN) and Health Care Centers (HCC) Participating in Experiments with New Modes of Remuneration (ENMR). Questions d'économie de la Santé. 2015.

13. Barnett M, Frank J, Wehring H, Newland B, VonMuenster S, Kumbera P, et al. Analysis of PharmacistProvided Medication Therapy Management(MTM) Services in Community Pharmacies Over 7 Years. JMCP. 2009;15:18-31.

14. Bradley F, Seston E, Mannall C, Cutts C. Evolution of the general practice pharmacist's role in England: a longitudinal study. Br J Gen Pract. 2018;:bjgp18 × 698849 .

15. Bokhof B, Junius-Walker U. Reducing Polypharmacy from the Perspectives of General Practitioners and Older Patients: A Synthesis of Qualitative Studies. Drugs Aging. 2016;33:249-66.

16. Laursen J, Kornholt J, Betzer C, Petersen TS, Christensen MB. General Practitioners' Barriers Toward Medication Reviews in Polymedicated Multimorbid Patients. Health Serv Res Manag Epidemiol. 2018;5.

17. Carrier H, Zaytseva A, Bocquier A, Villani P, Verdoux H, Fortin M, et al. GPs' management of polypharmacy and therapeutic dilemma in patients with multimorbidity: a cross-sectional survey of GPs in France. $\mathrm{Br} \mathrm{J}$ Gen Pract. 2019;69:e270-8.

18. Verger P, Collange F, Fressard L, Bocquier A, Gautier A, Pulcini C, et al. Prevalence and correlates of vaccine hesitancy among general practitioners: a cross-sectional telephone survey in France, April to July 2014. Eurosurveillance. 2016;21.

19. McCarthy G, Cornally N, Moran J, Courtney M. Practice nurses and general practitioners: perspectives on the role and future development of practice nursing in Ireland. J Clin Nurs. 2012;21:2286-95. 
20. Supper I, Bourgueil Y, Ecochard R, Letrilliart L. Impact of multimorbidity on healthcare professional task shifting potential in patients with type 2 diabetes in primary care: a French cross-sectional study. BMJ Open. 2017;7.

21. Michot P, Catala O, Supper I, Boulieu R, Zerbib Y, Colin C, et al. Cooperation between general practitioners and pharmacists: a systematic review. Santé Publique. 2013;25:331-41.

22. Nkansah N, Mostovetsky O, Yu C, Chheng T, Beney J, Bond CM, et al. Effect of outpatient pharmacists' nondispensing roles on patient outcomes and prescribing patterns. Cochrane Database of Systematic Reviews. 2010.

23. Chisholm-Burns MA, Kim Lee J, Spivey CA, Slack M, Herrier RN, Hall-Lipsy E, et al. US pharmacists' effect as team members on patient care: systematic review and meta-analyses. Med Care. 2010;48:923-33.

24. Dey RM, Vries MJW de, Bosnic-Anticevich S. Collaboration in chronic care: unpacking the relationship of pharmacists and general medical practitioners in primary care. Int J Pharm Pract. 2011;19:21-9.

25. Wüstmann A-F, Haase-Strey C, Kubiak T, Ritter CA. Cooperation between community pharmacists and general practitioners in eastern Germany: attitudes and needs. Int J Clin Pharm. 2013;35:584-92.

26. Blondal AB, Jonsson JS, Sporrong SK, Almarsdottir AB. General practitioners' perceptions of the current status and pharmacists' contribution to primary care in Iceland. Int J Clin Pharm. 2017;39:945-52.

27. Löffler C, Koudmani C, Böhmer F, Paschka SD, Höck J, Drewelow E, et al. Perceptions of interprofessional collaboration of general practitioners and community pharmacists - a qualitative study. BMC Health Serv Res. 2017;17.

28. Laurant M, Biezen M, van der, Wijers N, Watananirun K, Kontopantelis E, Vught AJ van. Nurses as substitutes for doctors in primary care. Cochrane Database of Systematic Reviews. 2018.

29. Curoe A, Kralewski J, Kaissi A. Assessing the Cultures of Medical Group Practices. The Journal of the American Board of Family Medicine. 2003;16:394-8.

30. Afrite A, Mousquès J. Forms of primary care teams - A typology of multidisciplinary group practices, health care networks. Questions d'économie de la Santé. 2014;:8.

31. AlRasheed MM, Alhawassi TM, Alanazi A, Aloudah N, Khurshid F, Alsultan M. Knowledge and willingness of physicians about deprescribing among older patients: a qualitative study. Clin Interv Aging. 2018;13:14018.

32. Smith SM, Soubhi H, Fortin M, Hudon C, O’Dowd T. Managing patients with multimorbidity: systematic review of interventions in primary care and community settings. BMJ. 2012;345(sep03 1):e5205-5.

33. Garth M, Millet A, Shearer E, Stafford S, Bereknyei Merrell S, Bruce J, et al. Interprofessional Collaboration: A Qualitative Study of Non-Physician Perspectives on Resident Competency. J Gen Intern Med. 2018;33:48792.

\section{Supplementary Files}

This is a list of supplementary files associated with this preprint. Click to download.

- AdditionalFileBMCFamilyPracticeFAMPD2000292.docx 